\title{
Editorial
}

\section{Special Issue High-Performance Eco-Efficient Concrete}

\author{
Carlos Thomas ${ }^{1, * \mathbb{D}}$, Jorge de Brito ${ }^{2}$ (D) and Valeria Corinaldesi ${ }^{3}$ (D) \\ 1 LADICIM, E.T.S. de Ingenieros de Caminos, Canales y Puertos, Universidad de Cantabria, \\ Av./Los Castros 44, 39005 Santander, Spain \\ 2 Instituto Superior Técnico, Universidade de Lisboa, Av. Rovisco Pais, 1049-001 Lisbon, Portugal; \\ jb@civil.ist.utl.pt \\ 3 Department of Materials, Università Politecnica delle Marche, Via Brecce Bianche 12, 60131 Ancona, Italy; \\ v.corinaldesi@univpm.it \\ * Correspondence: thomasc@unican.es
}

Citation: Thomas, C.; de Brito, J.; Corinaldesi, V. Special Issue High-Performance Eco-Efficient Concrete. Appl. Sci. 2021, 11, 1163. https://doi.org/10.3390/app11031163

Received: 1 January 2021

Accepted: 25 January 2021

Published: 28 January 2021

Publisher's Note: MDPI stays neutral with regard to jurisdictional claims in published maps and institutional affiliations.

Copyright: (c) 2021 by the authors. Licensee MDPI, Basel, Switzerland. This article is an open access article distributed under the terms and conditions of the Creative Commons Attribution (CC BY) license (https:// creativecommons.org/licenses/by/ $4.0 /)$.

\section{Introduction}

The benefits of recycling in the construction sector have been widely demonstrated and are unquestionable. The use of recycled aggregates, steel slags, and low-impact cements implies an important reduction of the environmental footprint, and eco-efficient concretes made with them must be a priority. However, these materials show, in some cases, losses of mechanical and durability behavior compared with natural materials. This is why we must invest our efforts in finding high-performance eco-efficient concretes that can compete-or even surpass-traditional concrete. To achieve this, research and dissemination of its results is essential. The objective of this Special Issue is to group the most recent and relevant research in relation to high-performance eco-efficient concrete into a single document. Subsequently, the possibility of publishing a book with the contributions of all authors will be assessed.

So far, 16 papers have been published in the Special Issue out of a total of 21 submitted. The next sections provide a brief summary of each of the papers published.

\section{High-Frequency Fatigue Testing of Recycled Aggregate Concrete}

Sainz-Aja et al. [1] show that concrete fatigue behavior has not been extensively studied, in part because of the difficulty and cost. Some concrete elements subjected to this type of load include the railway superstructure of sleepers or slab track, bridges for both road and rail track, and the foundations of wind turbine towers or offshore structures. In order to address fatigue problems, a methodology was proposed that reduces the lengthy testing time and high cost by increasing the test frequency up to the resonance frequency of the set formed by the specimen and the test machine. After comparing this test method with conventional frequency tests, it was found that tests performed at a high frequency $(90 \mathrm{~Hz})$ were more conservative than those performed at a moderate frequency $(10 \mathrm{~Hz})$; this effect was magnified in those concretes with recycled aggregates coming from crushed concrete (RC-S). In addition, it was found that the resonance frequency of the specimentest machine set was a parameter capable of identifying whether the specimen was close to failure.

\section{Mechanical and Durability Properties of Concrete with Coarse Recycled Aggregate Produced with Electric Arc Furnace Slag Concrete}

Tamayo et al. [2] show the search for more sustainable construction materials, capable of complying with quality standards and current innovation policies, aimed at saving natural resources and reducing global pollution, is one of the greatest present societal challenges. In this study, an innovative recycled aggregate concrete (RAC) is designed and produced based on the use of a coarse recycled aggregate (CRA) crushing concrete with electric arc furnace slags as aggregate. These slags are a by-product of the steelmaking 
industry and their use, which avoids the use of natural aggregates, is a new trend in concrete and pavement technology. This paper has investigated the effects of incorporating this type of CRA in concrete at several replacement levels $(0 \%, 20 \%, 50 \%$, and $100 \%$ by volume), by means of the physical, mechanical, and durability characterization of the mixes. The analysis of the results has allowed the benefits and disadvantages of these new CRAs to be established, by comparing them with those of a natural aggregate concrete (NAC) mix (with $0 \%$ CRA incorporation) and with the data available in the literature for concrete made with more common CRA, based on construction and demolition waste (CDW). Compared to NAC, similar compressive strength and tensile strength values for all replacement ratios have been obtained. The modulus of elasticity, the resistance to chloride penetration, and the resistance to carbonation are less affected by these CRA than when CRA from CDW waste is used. Slight increases in bulk density over $7 \%$ were observed for total replacement. Overall, functionally good mechanical and durability properties have been obtained.

\section{High Performance Self-Compacting Concrete with Electric Arc Furnace Slag Aggregate and Cupola Slag Powder}

Sosa et al. [3] present the development of self-compacting concretes with electric arc furnace slags is a novelty in the field of materials and the production of high-performance concretes with these characteristics is a further achievement. To obtain these high-strength, low-permeability concretes, steel slag aggregates and cupola slag powder are used. To prove the effectiveness of these concretes, they are compared with control concretes that use diabase aggregates, fly ash, and limestone supplementary cementitious materials (SCMs, also called fillers), and intermediate mix proportions. The high density SCMs give the fresh concrete self-compacting thixotropy using high-density aggregates with no segregation. Moreover, the temporal evolution of the mechanical properties of mortars and concretes shows pozzolanic reactions for the cupola slag. The fulfillment of the demands in terms of stability, flowability, and mechanical properties required for this type of concrete, and the savings of natural resources derived from the valorization of waste, make these sustainable concretes a viable option for countless applications in civil engineering.

\section{Economic and Technical Viability of Using Shotcrete with Coarse Recycled Concrete Aggregates in Deep Tunnels}

This work [4] analyzes the technical and economic viability of using coarse recycled aggregates from crushed concrete in shotcrete, as a primary lining support in tunnels. Four incorporation ratios of coarse natural aggregate (CNA) with coarse recycled concrete aggregates from concrete (CRCA) were studied: $0 \%, 20 \%, 50 \%$, and $100 \%$. The mechanical properties of the dry-mix shotcrete were obtained in an independent experimental campaign. Initially, the technical viability of CRCA shotcrete was validated for deep rock tunnels, based on the convergence-confinement method. Two cases were studied to determine the equivalent thickness for each combination of replacement ratio using CRCA shotcrete: (i) similar stiffness and (ii) similar yield stress. Subsequently, an economic assessment was performed. The stiffness criterion increased the thickness below $10 \%$ in both the $20 \%$ and $50 \%$ replacement ratios, which shows their technical viability with very marginal cost increase $(<5 \%)$. On the other hand, the maximum pressure criteria required higher increments, close to $30 \%$ in the $50 \%$ replacement ratio. A full replacement was proven impracticable in both analyses.

\section{Experimental Characterization of Prefabricated Bridge Deck Panels Prepared with Prestressed and Sustainable Ultra-High Performance Concrete}

Enhanced quality and reduced on-site construction time are the basic features of prefabricated bridge elements and systems [5]. Prefabricated lightweight bridge decks have already started finding their place in accelerated bridge construction (ABC). Therefore, the development of deck panels using high strength and high performance concrete has become an active area of research. Further optimization in such deck systems is possible using prestressing or replacement of raw materials with sustainable and recyclable materi- 
als. This research involves experimental evaluation of six full-depth precast prestressed high strength fiber-reinforced concrete (HSFRC) and six partial-depth sustainable ultrahigh performance concrete (sUHPC) composite bridge deck panels. The composite panels comprise UHPC prepared with ground granulated blast furnace slag (GGBS) with the replacement of $30 \%$ cement content overlaid by recycled aggregate concrete made with replacement of $30 \%$ of coarse aggregates with recycled aggregates. The experimental variables for six HSFRC panels were depth, level of prestressing, and shear reinforcement. The six sUHPC panels were prepared with different shear and flexural reinforcements and sUHPC-normal/recycled aggregate concrete interface. Experimental results exhibit the promise of both systems to serve as an alternative to conventional bridge deck systems.

\section{Alkali Activated Paste and Concrete Based on of Biomass Bottom Ash with Phosphogypsum}

There is a growing interest in the development of new cementitious binders for building construction activities. In this study, biomass bottom ash (BBA) was used as an aluminosilicate precursor and phosphogypsum (PG) was used as a calcium source [6]. The mixtures of BBA and PG were activated with the sodium hydroxide solution or the mixture of sodium hydroxide solution and sodium silicate hydrate solution. Alkali activated binders were investigated using X-ray powder diffraction (XRD), X-ray fluorescence (XRF), and scanning electron microscopy (SEM) test methods. The compressive strength of hardened paste and fine-grained concrete was also evaluated. After 28 days, the highest compressive strength reached $30.0 \mathrm{MPa}$ - when the BBA was substituted with $15 \%$ PG and activated with $\mathrm{NaOH}$ solution-which is $14 \mathrm{MPa}$ more than control sample. In addition, BBA fine-grained concrete samples based on BBA with 15\% PG substitute activated with $\mathrm{NaOH} / \mathrm{Na}_{2} \mathrm{SiO}_{3}$ solution showed higher compressive strength compered to when $\mathrm{NaOH}$ activator was used $15.4 \mathrm{MPa}$ and $12.9 \mathrm{MPa}$ respectfully. The $\mathrm{NaOH} / \mathrm{Na} 2 \mathrm{SiO}_{3}$ activator solution resulted reduced

\section{Mechanical Properties and Freeze-Thaw Durability of Basalt Fiber Reactive Powder Concrete}

Basalt fiber has a great advantage on the mechanical properties and durability of reactive powder concrete (RPC) because of its superior mechanical properties and chemical corrosion resistance. In this paper, basalt fiber was adopted to modified RPC, and plain reactive powder concrete (PRPC), basalt fiber reactive powder concrete (BFRPC) and steel fiber reactive powder concrete (SFRPC) were prepared [7]. The mechanical properties and freeze-thaw durability of BFRPC with different basalt fiber contents were tested and compared with PRPC and SFRPC to investigate the effects of basalt fiber contents and fiber type on the mechanical properties and freeze-thaw durability of RPC. Besides, the mass loss rate and compressive strength loss rate of RPC under two freeze-thaw conditions (fresh-water freeze-thaw and chloride-salt freeze-thaw) were tested to evaluate the effects of freeze-thaw conditions on the freeze-thaw durability of RPC. The experiment results showed that the mechanical properties and freeze-thaw resistance of RPC increased as the basalt fiber content increase. Compared with the fresh-water freeze-thaw cycle, the damage of the chloride-salt freeze-thaw cycle on RPC was great. Based on the freeze-thaw experiment results, it was found that SFRPC was sensitive to the corrosion of chloride salts and compared with the steel fiber, the improvement of basalt fiber on the freeze-thaw resistance of RPC was great.

\section{A Low-Autogenous-Shrinkage Alkali-Activated Slag and Fly Ash Concrete}

Alkali-activated slag and fly ash (AASF) materials are emerging as promising alternatives to conventional Portland cement. Despite the superior mechanical properties of AASF materials, they are known to show large autogenous shrinkage, which hinders the wide application of these eco-friendly materials in infrastructure. To mitigate the autogenous shrinkage of AASF, two innovative autogenous-shrinkage-mitigating admixtures, superabsorbent polymers (SAPs) and metakaolin (MK), are applied in this study [8]. The results 
show that the incorporation of SAPs and MK significantly mitigates autogenous shrinkage and cracking potential of AASF paste and concrete. Moreover, the AASF concrete with SAPs and MK shows enhanced workability and tensile strength-to-compressive strength ratios. These results indicate that SAPs and MK are promising admixtures to make AASF concrete a high-performance alternative to Portland cement concrete in structural engineering.

\section{Properties of Foamed Lightweight High-Performance Phosphogypsum-Based Ternary System Binder}

The potential of phosphogypsum (PG) as secondary raw material in construction industry is high if compared to other raw materials from the point of view of availability, total energy consumption, and $\mathrm{CO}_{2}$ emissions created during material processing. This work [9] investigates a green hydraulic ternary system binder based on waste phosphogypsum (PG) for the development of sustainable high-performance construction materials. Moreover, a simple, reproducible, and low-cost manufacture is followed by reaching PG utilization up to $50 \mathrm{wt} . \%$ of the binder. Commercial gypsum plaster was used for comparison. Highperformance binder was obtained, and on a basis of it, foamed lightweight material was developed. Low water-binder ratio mixture compositions were prepared. Binder paste, mortar, and foamed binder were used for sample preparation. Chemical, mineralogical composition, and performance of the binder were evaluated. Results indicate that the used waste may be successfully employed to produce high-performance binder pastes and even mortars with a compression strength up to $90 \mathrm{MPa}$. With the use of foaming agent, lightweight $\left(370-700 \mathrm{~kg} / \mathrm{m}^{3}\right)$ foam concrete was produced with a thermal conductivity from 0.086 to $0.153 \mathrm{~W} / \mathrm{mK}$. Water tightness (softening coefficient) of such foamed material was $0.5-0.64$. The proposed approach represents a viable solution to reduce the environmental footprint associated with waste disposal.

\section{Effect of Fly Ash as Cement Replacement on Chloride Diffusion, Chloride Binding Capacity, and Micro-Properties of Concrete in a Water Soaking Environment}

This paper [10] experimentally studies the effects of fly ash on the diffusion, bonding, and micro-properties of chloride penetration in concrete in a water soaking environment based on the natural diffusion law. Different fly ash replacement ratio of cement in normal concrete was investigated. The effect of fly ash on chloride transportation, diffusion, coefficient, free chloride content, and binding chloride content were quantified, and the concrete porosity and microstructure were reported through mercury intrusion perimetry and scanning electron microscopy, respectively. It was concluded from the test results that fly ash particles and hydration products (filling and pozzolanic effects) led to the densification of microstructures in concrete. The addition of fly ash greatly reduced the deposition of chloride ions. The chloride ion diffusion coefficient considerably decreased with increasing fly ash replacement, and fly ash benefits the binding of chloride in concrete. Additionally, a new equation is proposed to predict chloride-binding capacity based on the test results.

\section{Durability Assessment of Recycled Aggregate HVFA Concrete}

The possibility of producing high-volume fly ash (HVFA) recycled aggregate concrete represents an important step towards the development of sustainable building materials. In fact, there is a growing need to reduce the use of non-renewable natural resources and, at the same time, to valorize industrial by-products, such as fly ash, which would otherwise be sent to the landfill. The present experimental work [11] investigates the physical and mechanical properties of concrete by replacing natural aggregates and cement with recycled aggregates and fly ash, respectively. First, the mechanical properties of four different mixtures have been analyzed and compared. Then, the effectiveness of recycled aggregate and fly ash on reducing carbonation and chloride penetration depth has been also evaluated. Finally, the corrosion behavior of the different concrete mixtures, reinforced with either bare or galvanized steel plates, has been evaluated. The results obtained show that highvolume fly ash (HVFA) recycled aggregate concrete can be produced without significative 
reduction in mechanical properties. Furthermore, the addition of high-volume fly ash and the total replacement of natural aggregates with recycled ones did not modify the corrosion behavior of embedded bare and galvanized steel reinforcement.

\section{Mechanical Properties and Flexural Behavior of Sustainable Bamboo Fiber-Reinforced Mortar}

In this study [12], a sustainable mortar mixture is developed using renewable byproducts for the enhancement of mechanical properties and fracture behavior. A highvolume of fly ash - a by-product of coal combustion-is used to replace Portland cement, while waste by-products from the production of engineered bamboo composite materials are used to obtain bamboo fibers and to improve the fracture toughness of the mixture. The bamboo process waste was ground and size-fractioned by sieving. Several mixes containing different amounts of fibers were prepared for mechanical and fracture toughness assessment, evaluated via bending tests. The addition of bamboo fibers showed insignificant losses of strength, resulting in mixtures with compressive strengths of $55 \mathrm{MPa}$ and above. The bamboo fibers were able to control crack propagation and show improved crack-bridging effects with higher fiber volumes, resulting in a strain-softening behavior and mixture with higher toughness. The results of this study show that the developed bamboo fiber-reinforced mortar mixture is a promising sustainable and affordable construction material with enhanced mechanical properties and fracture toughness with the potential to be used in different structural applications, especially in developing countries.

\section{Industrial Low-Clinker Precast Elements Using Recycled Aggregates}

Increasing amounts of sustainable concretes are being used as society becomes more aware of the environment. This paper [13] attempts to evaluate the properties of precast concrete elements formed with recycled coarse aggregate and low clinker content cement using recycled additions. To this end, six different mix proportions were characterized: a reference concrete; two concretes with $25 \%$ wt. and $50 \%$ wt. substitution of coarse aggregate made using mixed construction and demolition wastes; and others with recycled cement with low clinker content. The compressive strength, the elastic modulus, and the durability indicator decrease with the proportions of recycled aggregate replacing aggregate, and it is accentuated with the incorporation of recycled cement. However, all of the precast elements tested show good performance with slight reduction in the mechanical properties. To confirm the appropriate behavior of New Jersey precast barriers, a test that simulated the impact that simulated the impact of a vehicle was carried out.

\section{Photocatalytic Recycled Mortars: Circular Economy as a Solution for Decontamination}

The circular economy is an economic model of production and consumption that involves reusing, repairing, refurbishing, and recycling materials after their service life. The use of waste as secondary raw materials is one of the actions to establish this model. Construction and demolition waste (CDW) constitute one of the most important waste streams in Europe due to its high production rate per capita. Aggregates from these recycling operations are usually used in products with low mechanical requirements in the construction sector. In addition, the incorporation of photocatalytic materials in construction has emerged as a promising technology to develop products with special properties, such as air decontamination. This research [14] aims to study the decontaminating behavior of mortars manufactured with the maximum amount of mixed recycled sand without affecting their mechanical properties or durability. For this, two families of mortars were produced, one consisting of traditional Portland cement and the other of photocatalytic cement, each with four replacement rates of natural sand by mixed recycled sand from CDW. Mechanical and durability properties, as well as decontaminating capacity, were evaluated for these mortars. The results show adequate mechanical behavior, despite the incorporation of mixed recycled sand, and improved decontaminating capacity by means of NOx reduction capacity. 


\section{Durability of High Volume Glass Powder Self-Compacting Concrete}

The transport characteristics of waste glass powder incorporated self-compacting concrete (SCC) for a number of different durability indicators are reported in this paper [15] SCC mixes were cast at a water to binder ratio of 0.4 using glass powders with a mean particle size of 10, 20, and $40 \mu \mathrm{m}$, and at cement replacement levels of 20,30, and $40 \%$. The oxygen permeability, electrical resistivity, porosity, and chloride diffusivity were measured at different ages from 3 to 545 days of curing. The amount and particle size of the incorporated waste glass powder was found to influence the durability properties of SCC. The glass incorporated SCC mixes showed similar or better durability characteristics compared to general purpose (GP) and fly ash mixes at similar cement replacement level. A significant improvement in the transport properties of the glass SCC mixes was observed beyond 90 days.

\section{High-Durability Concrete Using Eco-Friendly Slag-Pozzolanic Cements and Recycled Aggregate}

Clinker production is very energy-intensive and responsible for releasing climaterelevant carbon dioxide $\left(\mathrm{CO}_{2}\right)$ into the atmosphere, and the exploitation of aggregate for concrete results in a reduction in natural resources. This contrasts with infrastructure development, surging urbanization, and the demand for construction materials with increasing requirements in terms of durability and strength. A possible answer to this is eco-efficient, high-performance concrete. This article [16] illustrates basic material investigations to both, using eco-friendly cement and recycled aggregate from tunneling to produce structural concrete and inner shell concrete, showing high impermeability and durability. By replacing energy- and $\mathrm{CO}_{2}$-intensive cement types by slag-pozzolanic cement (CEM V) and using recycled aggregate, a significant contribution to environmental sustainability can be provided while still meeting the material requirements to achieve a service lifetime for the tunnel structure of up to 200 years. Results of this research show that alternative cements (CEM V), as well as processed tunnel spoil, indicate good applicability in terms of their properties. Despite the substitution of conventional clinker and conventional aggregate, the concrete shows good workability and promising durability in conjunction with adequate concrete strengths.

Author Contributions: Conceptualization, C.T.; methodology, C.T. and J.d.B.; validation, C.T., J.d.B. and V.C. All authors have read and agreed to the published version of the manuscript.

Funding: This research received no external funding.

Acknowledgments: Thanks are due to all of the authors and peer reviewers for their valuable contributions to this Special Issue. The MDPI management and staff are also to be congratulated for their untiring editorial support for the success of this project.

Conflicts of Interest: The authors declare no conflict of interest.

\section{References}

1. Sainz-Aja, J.; Thomas, C.; Polanco, J.A.; Carrascal, I. High-Frequency Fatigue Testing of Recycled Aggregate Concrete. Appl. Sci. 2019, 10, 10. [CrossRef]

2. Tamayo, P.; Pacheco, J.; Thomas, C.; De Brito, J.; Rico, J. Mechanical and Durability Properties of Concrete with Coarse Recycled Aggregate Produced with Electric Arc Furnace Slag Concrete. Appl. Sci. 2019, 10, 216. [CrossRef]

3. Sosa, I.; Thomas, C.; Polanco, J.A.; Setién, J.; Tamayo, P. High Performance Self-Compacting Concrete with Electric Arc Furnace Slag Aggregate and Cupola Slag Powder. Appl. Sci. 2020, 10, 773. [CrossRef]

4. Duarte, G.; Gomes, R.; De Brito, J.; Miguel, B.; Nobre, J. Economic and Technical Viability of Using Shotcrete with Coarse Recycled Concrete Aggregates in Deep Tunnels. Appl. Sci. 2020, 10, 2697. [CrossRef]

5. Zafar, M.N.; Saleem, M.; Xia, J.; Saleem, M. Experimental Characterization of Prefabricated Bridge Deck Panels Prepared with Prestressed and Sustainable Ultra-High Performance Concrete. Appl. Sci. 2020, 10, 5132. [CrossRef]

6. Vaičiukynienè, D.; Nizevičienè, D.; Kantautas, A.; Bocullo, V.; Kielè, A. Alkali Activated Paste and Concrete Based on of Biomass Bottom Ash with Phosphogypsum. Appl. Sci. 2020, 10, 5190. [CrossRef]

7. Li, W.; Liu, H.; Zhu, B.; Lyu, X.; Gao, X.; Liang, C. Mechanical Properties and Freeze-Thaw Durability of Basalt Fiber Reactive Powder Concrete. Appl. Sci. 2020, 10, 5682. [CrossRef] 
8. Li, Z.; Yao, X.; Chen, Y.; Lu, T.; Ye, G. A Low-Autogenous Shrinkage Alkali-Activated Slag and Fly Ash Concrete. Appl. Sci. 2020, 10, 6092. [CrossRef]

9. Bumanis, G.; Zorica, J.; Bajare, D. Properties of Foamed Lightweight High-Performance Phosphogypsum-Based Ternary System Binder. Appl. Sci. 2020, 10, 6222. [CrossRef]

10. Liu, J.; Liu, J.; Huang, Z.-Y.; Zhu, J.-H.; Liu, W.; Zhang, W. Effect of Fly Ash as Cement Replacement on Chloride Diffusion, Chloride Binding Capacity, and Micro-Properties of Concrete in a Water Soaking Environment. Appl. Sci. 2020, $10,6271$. [CrossRef]

11. Corinaldesi, V.; Donnini, J.; Giosuè, C.; Mobili, A.; Tittarelli, F. Durability Assessment of Recycled Aggregate HVFA Concrete. Appl. Sci. 2020, 10, 6454. [CrossRef]

12. Maier, M.; Javadian, A.; Saeidi, N.; Unluer, C.; Taylor, H.; Ostertag, C.P. Mechanical Properties and Flexural Behavior of Sustainable Bamboo Fiber-Reinforced Mortar. Appl. Sci. 2020, 10, 6587. [CrossRef]

13. Thomas, C.; Cimentada, A.I.; Cantero, B.; Medina, C.; Polanco, J.A. Industrial Low-Clinker Precast Elements Using Recycled Aggregates. Appl. Sci. 2020, 10, 6655. [CrossRef]

14. Barbudo, A.; Lozano-Lunar, A.; López-Uceda, A.; Galvin, A.P.; Ayuso, J. Photocatalytic Recycled Mortars: Circular Economy as a Solution for Decontamination. Appl. Sci. 2020, 10, 7305. [CrossRef]

15. Tariq, S.; Scott, A.N.; MacKechnie, J.R.; Shah, V. Durability of High Volume Glass Powder Self-Compacting Concrete. Appl. Sci. 2020, 10, 8058. [CrossRef]

16. Voit, K.; Zeman, O.; Janotka, I.; Adamcova, R.; Bergmeister, K. High-Durability Concrete Using Eco-Friendly Slag-Pozzolanic Cements and Recycled Aggregate. Appl. Sci. 2020, 10, 8307. [CrossRef] 